\section{Nuevos sujetos en la narrativa urbana}

\author{
Antonio González Montes
}

a narrativa literaria posee una gran L capacidad para modelar artísticamente los más diversos aspectos, niveles y sucesos que los escritores imaginan y plasman en el espacio breve y concentrado del cuento o en el amplio y complejo de la novela. Estas dos especies gozan de la preferencia de escritores y de lectores y contribuyen a mantener, enriquecer y modificar el imaginario que comparten los miembros de una sociedad. Tal ocurre, por ejemplo, con la literatura peruana, la cual recoge en sus textos y obras más representativos los más variados rostros, sentimientos, espacios y hechos del inabarcable y heterogéneo universo sociocultural peruano.

En las siguientes líneas nos proponemos acercarnos a un conjunto de textos que pertenecen a nuestra narrativa breve última, con el propósito de examinar el modo en que en dichos textos emergen algunos de los nuevos sujetos, que enriquecen el repertorio humano que pulula en el espacio conflictivo del ámbito urbano nacional. Sabemos que desde mediados del siglo pasado se ha operado en el país una gran transformación, entre otras, la cual consiste en que el sector urbano ha devenido en más importante que el rural.

El fenómeno migratorio del campo a la ciudad, propiciado por factores internos y externos, ha determinado que el crecimiento demográfico, la economía, la dinámica social y cultural se aceleren en el mundo de las urbes. 
Estas han experimentado un proceso de configuración muy contradictorio, porque, sin duda, se han modernizado al impulso del fenómeno de la globalización, pero han incorporado en su perfil elementos que proceden del espacio rural y que coexisten con todos los otros componentes que dibujan el rostro heterogéneo $\mathrm{y}$, a veces, irreconocible de los seres humanos que se desplazan por las congestionadas arterias de las ciudades de principios de milenio. Y como consecuencia de los inconmensurables cambios provocados por las innovaciones informáticas, el planeta, casi en su totalidad, ha devenido en una gran aldea, como quería McLuhan. Mas esta nueva realidad no ha significado, necesariamente, una integración armoniosa de las partes de esta totalidad planetaria. Muy por el contrario, se ha generado un movimiento de ebullición y de efervescencia cuyos resultados son impredecibles.

Es esta situación inédita, o parte de ella, la que nuestra actual narrativa breve recoge y recrea con autenticidad y audacia, como corresponde a los fueros del arte literario, que siempre se ha esforzado por plasmar las imágenes más inquietantes y provocadoras de lo que constituye el perfil del confuso y fragmentado mundo de hoy.
Los cuentos que analizaremos brevemente muestran —de forma concreta e imaginativa - realidades verosímiles que son contundentes metáforas y alegorías del modo de ser y de actuar de los hombres y mujeres que viven o sobreviven en el erizado y espeluznante ámbito de las ciudades actuales.

\section{El escritor en la urbe actual}

Para ilustrar una de las formas de existencia de un escritor de ficciones en una ciudad que puede ser Lima o cualquier otra, situada en algún lugar del Tercer Mundo, hemos elegido "Dinosaurios", breve pero sustancioso relato del conocido narrador Antonio Gálvez Ronceros. ${ }^{1}$ La primera frase del texto nos permite conocer la ubicación de dicho personaje: "Son las dos de la madrugada y el escritor se halla en un cuartito, sentado a una mesa; el cuartito forma con otros dos una pequeña casa en un extremo de la ciudad".

Podemos apreciar que el autor ha elegido el punto de vista de un narrador en tercera persona omnisciente, el cual, a su vez, presenta a un escritor en el trance de imaginar una historia y de plasmarla verbalmente, como en efecto lo hace. Nos encontramos, pues, frente a un texto narrativo que

1 GÁLVEZ RONCEROS, Antonio. Cuaderno de agravios y lamentaciones. Lima: Universidad Nacional Mayor de San Marcos, 2003. 
nos muestra el proceso de gestación y de nacimiento de otro de igual naturaleza, de modo que "Dinosaurios" asume el carácter de pieza metanarrativa en tanto relata el hecho de relatar, y con ello logra que ambas anécdotas se entremezclen y se iluminen mutuamente, como si fueran la una espejo de la otra.

En cuanto a la historia en sí, está encarnada por dos personajes que aparecen sucesivamente sin ninguna relación entre ellos, aunque después se aprecie que son como dos caras de una misma moneda. El escritor describe al primero de los protagonistas y la imagen que ofrece de él es semejante a la suya, tal como nos la muestran las palabras del narrador en tercera persona omnisciente, reproducidas líneas antes. Veamos la similitud: "En el centro de una habitación un hombre permanece inmóvil en una humilde silla de palos, junto a una mesita, mirando desconsolado como si meditara en una desgracia. El hombre parece tener setenta años".

La descripción del personaje se completa con la de la modesta casa en la que este habita junto con su numerosa familia. Empero, el proceso de escritura acerca de este "hombre" se detiene y el escritor ocupa su mente en "ver" la aparición del otro protagonista de la historia: un individuo "algo gordo, rigurosamente acicalado" que está instalado en la cómoda y lujosa habi- tación de un hotel que pertenece a una cadena internacional. Las imágenes sobre este "individuo" se suceden y así se le puede observar leyendo el libro Cómo triunfar en los negocios, en el que hay consejos para alcanzar el éxito anhelado en dicho campo.

Y este propósito se ve reforzado por el hecho de que "el escritor ve ahora que el individuo se encuentra simultáneamente en cuarenta habitaciones del hotel. Todos tienen un ejemplar del libro. Ahora salen de sus habitaciones llevando el libro y se dirigen hacia un gran salón donde espera una larga mesa servida con viandas exquisitas". También observa el narrador testigo que los miembros de este grupo, antes de sentarse a la mesa, dictan una orden a sendos asistentes, los cuales se dirigen hacia la calle "y entregan a un enjambre de mensajeros miles de sobres lacrados. Una interminable columna de automóviles aguarda. Cada mensajero aborda de prisa uno. Se encienden los motores, y los vehículos se alejan en distintas direcciones".

Esta situación desconcierta al escritor e intenta volver al texto que había estado desarrollando acerca del "hombre del arenal", pero su propósito de retomar la escritura se frustra porque su imaginación lo fuerza a ver que uno de los mensajeros está tocando la puerta de la casa del primer personaje. De este modo las vidas de los dos protagonistas se juntan, pues el sobre con los mensa- 
jes es para el dueño de casa, y aunque este se resiste a recibirlo, finalmente lo hace "y extrae dos hojas de papel. Una contiene la relación de los nuevos precios -exorbitantes, elevadísimos- de productos alimenticios y farmacéuticos. La otra hoja dice brutalmente: 'Está usted despedido del trabajo'".

Las escenas finales del relato, imaginadas mas no registradas en el papel por el escritor, representan al hombre del arenal y al mensajero en una situación de tensión, ya que el primero se extraña de que el otro aún permanezca en actitud de espera y este último informa que debe llevar una respuesta a quienes lo han enviado. El destinatario del mensaje "considera que eso ya es el colmo, no otra cosa que sadismo" y adoptando una actitud presta y decidida, que parece contradecir la decrepitud de sus setenta años y simbolizar el empuje de uno de treinta, envía un mensaje contundente para quienes lo han privado de su derecho al trabajo: "Dígales que los dinosaurios se extinguieron porque su monstruosidad creció demasiado".

El escritor que ha "visto" y "oído" al hombre del arenal "llega a la conclusión de que seguir escribiendo la historia que había concebido, ya no tiene ningún sentido". Lo dicho por su primer personaje resulta suficiente para cerrar esta anécdota que enfrenta a los dos actores principales del sistema socioeconómico actual: el trabajador y el empre- sario, que aunque son parte de un todo tienen intereses contrapuestos. El primero quiere ejercer su derecho al trabajo, con la finalidad de realizarse como ser humano y garantizarse una vida digna para sí y los suyos. El hombre de negocios, a su vez, pretende maximizar sus ganancias económicas, aunque ello conlleve privar del derecho a trabajar de millones de seres humanos.

De modo alegórico y sobrio el escritor real y viviente que es Antonio Gálvez Ronceros ha evidenciado una de las contradicciones fundamentales de la sociedad actual. Nos ha recordado que los avances tecnológicos hacen cada vez más innecesaria la mano de obra, por lo cual el despido y el desempleo masivos son realidades con las que tienen que contar los trabajadores de cualquier nivel y actividad. Pero también nos advierte sobre los peligros de un sistema que por su voracidad lucrativa puede terminar destruyéndose a sí mismo. Gálvez Ronceros ofrece, pues, un testimonio artístico sobre una realidad ineludible en el mundo globalizado de hoy y lo hace de un modo equilibrado y lúcido, sin estridencias ni exageraciones, pero sí con firmeza e imaginación creadora.

\section{La mujer en la urbe actual: El ser $y$ el parecer}

Abordaremos la lectura del cuento "Cuando el río suena", del destacado 
escritor Carlos Rengifo (Lima, 1964). ${ }^{2}$ La anécdota es insólita pero verosímil: un narrador en tercera persona omnisciente muestra el complejo proceso a través del cual una mujer de clase media, y que trabaja, llega a convertirse en prostituta. Este cambio en la condición del personaje se produce como una respuesta final a las reiteradas insinuaciones que recibe en la calle, mientras se desplaza de su centro laboral a su casa o viceversa. El relato da cuenta de, por lo menos, tres oportunidades en las que es abordada por peatones diferentes, quienes asumiendo que ella es una "mujer de la calle" le solicitan sus "servicios".

Estas desagradables escenas sumen al principio a Julia - ese es su nombreen una profunda crisis pues ella no es prostituta y cree no parecerlo, por lo cual le extraña haber recibido semejantes ofertas. Trata de descubrir las razones por las que su apariencia personal proyecta una imagen equívoca, mas no llega a descubrirlo: "Se miró al espejo de cuerpo entero, intrigada de no ver un rasgo de sensualidad o morbidez en su forma de vestir. Entonces ¿qué pasaba? A lo mejor era el maquillaje. Sí, seguro que era eso. Pero Julia no se pintaba mucho, apenas unos toquecitos y ya. De modo que no pudo salir de su desconcierto".

Esta situación de perplejidad se acrecienta a lo largo del relato y afecta la vida y la autoestima del personaje. Hace más conflictivo su diario existir en su casa, en el trabajo, y sobre todo en la calle, que es donde sigue sufriendo las agresiones gratuitas que agravian su dignidad de mujer y de trabajadora. Sus reacciones son contradictorias y desconcertantes, pues por un lado se siente incapaz de contarles a sus amigas y compañeras de labores el drama que le ocurre, pero, por otro lado, en una ocasión en que recibió una nueva insinuación indecorosa pasó por alto la ofensa y quiso satisfacer su curiosidad: le preguntó al desconocido "por qué había venido hacia ella". Este no solo no le dio una respuesta adecuada, sino que "la mandó a rodar"; Julia acusó fuertemente la agresión y su autoestima sufrió un nuevo descenso.

Paulatinamente la protagonista, aunque no sin grandes conflictos internos, fue cambiando su rechazo hacia las proposiciones indecentes por una actitud de expectativa: "De pronto se vio esperando a que

2 Este relato pertenece a su libro Criaturas de la sombra (Lima: Gaviota Azul Editores, 1998). Nosotros hemos trabajado con la versión que aparece en El cuento peruano 1990-2000. Selección, prólogo y notas de Ricardo González Vigil (Lima: Ediciones Copé, 2001). Carlos Rengifo ha publicado varios libros de cuentos y ha merecido distinciones en importantes concursos. 
alguien le hablara en el paradero, y miraba de cuando en cuando, sin ningún disimulo, a los jóvenes que le gustaban”. Finalmente cedió a lo que parecía "un dominio inexplicable que era mucho más fuerte que ella" y culminó su transformación aceptando la oferta que le hizo un hombre de "aliento alcohólico", a quien acompañó "a un hostal cercano".

Se ha terminado, pues, de operar un proceso de cambio interno provocado por una confluencia de factores intrínsecos y extrínsecos, como lo sugiere el propio título del relato. En efecto, la locución "Cuando el río suena" debe entenderse como que Julia era "una mujer prostituible"; las insinuaciones que recibió en la calle no hicieron sino despertar en ella una tendencia íntima que al comienzo rechazaba por razones morales, pero que luego dejó de lado para ejercer aquello que la llamaba desde el fondo de su ser.

Y así se consuma este tránsito, de modo gradual, con retrocesos pero al final de modo irreversible.

Rengifo maneja bien el conflicto que vive la personalidad de Julia y lo conduce hasta un desenlace sorpren- dente y a la vez verosímil. En suma, el relato es valioso porque ilustra el motivo siempre interesante de las relaciones hombre-mujer en el espacio de las calles. Permite apreciar la importancia de una serie de lenguajes verbales y no verbales que unos y otras usan para interactuar y hacer posible el acercamiento o la distancia: el diálogo al paso, la gestualidad de la cara y del cuerpo, el maquillaje, la vestimenta, el espacio. ${ }^{3}$

Ciertamente, también es pertinente reflexionar acerca del tema del cuerpo femenino en las sociedades masmediáticas actuales. El cine, la fotografía, la televisión, la publicidad, el periodismo otorgan un lugar protagónico a la figura de la mujer y destacan no solo la belleza de esta sino su sensualidad y erotismo; en general se la considera como un objeto meramente sexual. En "Cuando el río suena" también existe esta misma concepción: quienes tratan de establecer una relación con Julia no la ven como a un ser humano, sino como una mercancía que pueden comprar por una suma de dinero, y si ella se rebela en contra de esta ofensa a su dignidad, el agresor no tiene mejor idea que recurrir a los códigos típicos del

3 En ese sentido sería interesante hacer un análisis de "Cuando el río suena" desde los puntos de vista de la cinética y de la prosémica, dos disciplinas que forman parte de la semiótica y que se ocupan del estudio de los signos humanos basados en el movimiento (cinética) y en el espacio (prosémica). Cf. ZECCHETTO, Víctor. La danza de los signos / Nociones de semiótica general. Buenos Aires: Editorial La Crujía, 2003. 
machismo y le espeta la siguiente frase: "Vamos, preciosura, no te hagas la estrecha".

Finalmente, cabría establecer un nexo entre la realidad y la ficción. Si en el relato analizado resulta verosímil que una mujer de apariencia honesta sea abordada en varias ocasiones y en distintos lugares de la calle y reciba proposiciones como las que hacen mortificarse sinceramente a Julia, ello puede tener que ver con el hecho de que, sobre todo por razones económicas -el desempleo y sus consecuencias - la prostitución femenina se ha convertido en un fenómeno mucho más extendido y público. Existen -en ciudades como Lima- zonas céntricas en las que el ejercicio del llamado comercio carnal se realiza todos los días de la semana y durante las 24 horas. Este es el contexto en el que hay que situar e interpretar el sentido de una historia como la que vive Julia en los escenarios callejeros por los que se desplaza, en razón de ser una mujer que realiza un trabajo dependiente para poder atender sus necesidades y las de su familia. La complejidad del proceso interno que sufre y el cambio que experimenta podrían ser abordados complementariamente desde una perspectiva psicológica.

\section{El trabajo del periodista y las historias macabras}

El relato que analizaremos a continuación también tiene como uno de sus ejes temáticos un cuerpo femenino, pero no desde una óptica erótica sino macabra, enfoque que resulta muy recurrente en el periodismo de hoy, como podemos constatarlo casi cotidianamente en los diarios y telenoticieros que consumimos. Por eso esta historia, aunque tétrica, merece ser examinada, especialmente por la maestría con que está contada y por su carácter representativo de la realidad urbana actual, en la que el periodismo escrito y audiovisual ha asumido un papel dominante en la formación de nuestra visión del mundo.

En este caso específico es necesario saber el modo en que nació este cuento titulado "La comisión", publicado en el libro Tres historias del pueblo de Dios (Otras noticias del paraíso).4 Precisamente, el citado relato surgió a partir del proyecto de "tres conocidos narradores (que) decidieron contar la misma historia (una horrenda carnicería) utilizando estrategias y recursos narrativos diversos, enfatizando diferentes aspectos de los sucesos abordados, dando origen a tres cuentos artísticamente

4 Los autores de este singular volumen son Rafael Gutarra León, Sigifredo Burneo Sánchez y Houdini Guerrero Torres. Piura: Sietevientos Editores, 2000. 
muy diferenciados y, por cierto, bastante logrados. Cabe el placer de leerlos como un tríptico o un terceto". 5

Los propios autores señalan que "las tres narraciones que integran este volumen fueron posibles gracias a las informaciones orales del profesor José David Villalta Sosa, quien, durante una noche de verano, entretuvo a los autores con las incidencias, reales o ya fabuladas, del dramático protagonista de estas historias". De modo que nos encontramos ante un relato cuya composición ha seguido un proceso de varias fases y al narrador le interesa mostrar el camino que lo llevó hasta la fuente del suceso, que no es otra que el personaje que cometió "una horrenda carnicería", por la cual purga una condena en la celda de una cárcel de una ciudad (Piura), aunque el crimen se cometió en otra (Tumbes).

En cuanto a su estructura narrativa "La comisión" se plantea exactamente como un encargo que un periodista, Darío Guerra, debe cumplir como parte de su quehacer profesional en el diario donde trabaja. Su jefe le ha ordenado "que escriba un artículo de dos páginas para el suplemento dominical: "que sea bueno, carajo". Ante esta exigencia el personaje narrador baraja varias posibilidades y luego de evaluarlas decide investigar la historia que la noche anterior refirió David y que tiene como protagonista a "un tal Valento". Después de aclarar las circunstancias en que David conoció al asesino recluso, el periodista se propone tomar contacto directo con este; reconoce que "el relato de David fue bueno, pero siento que mi artículo ganará más si entrevisto al propio Valento".

En efecto, Darío Guerra llega al penal y consigue hablar con el autor del terrible asesinato, quien le detalla el modo en que cometió el execrable crimen contra su esposa.

En síntesis, el uxoricida quitó la vida y descuartizó a su cónyuge y las partes seccionadas las utilizó para atender a los asistentes a una parrillada organizada con el propósito de recaudar fondos para comprar medicinas para la víctima. El narrador de este abominable hecho no muestra mayor arrepentimiento; confiesa haber actuado no por odio a su pareja, sino por hastío: "Usted no se imagina - le dice a su estupefacto oyente- cómo jodía esa mujer; siempre la misma cantaleta, no hay plata para esto, no hay plata para el otro, estoy enferma y tú no te preocupas".

Esta situación límite llevó, pues, al delito a Valento, personaje que pertenece a los estratos pobres de la ciudad

5 GONZÁLEZ VIGIL, Ricardo. El cuento peruano 1990-2000. Lima: Ediciones Copé, 2001, p. 806. 
en la que vive. Ello se manifiesta en la variedad de oficios que ejerció: soldador, carpintero, carnicero. Según el comentario del periodista, también muestra habilidad para la narración; por eso le atribuye el calificativo de "medio poeta".

Habría que puntualizar que esta calificación también le alcanza al autor de "La comisión", ${ }^{6}$ pues la historia, de por sí desagradable y repulsiva, está contada con sabiduría y sobriedad. Si bien hay pasajes de crudo realismo, estos elementos se justifican en función del propósito del narrador de dejar que el propio protagonista cuente la tragedia personal y familiar que lo envolvió.

Darío Guerra, que "oye" la anécdota de boca de Valento, se limita a transcribir lo que este va desenvolviendo. El encuentro mismo entre periodista y entrevistado está contextualizado con verosimilitud y permite conocer no solo lo que cada uno dice, sino lo que sienten frente a una experiencia límite. El impacto de lo escuchado es de tal magnitud que el entrevistador manifiesta no estar seguro de llegar "a escribir la nota", aunque ya la ha escrito para quienes leemos la anécdota y sentimos la misma desazón de quien la escuchó en el penal. Pero el relato acaba con una nota irónica que le agrega densidad y humor negro a la anécdota: "Creo que hoy no almorzaré ni cenaré. Lo único que es seguro es que no vuelvo a asistir a ninguna parrillada, así sea gratis".

Podemos señalar que estamos ante una historia impactante y redonda desde el punto de vista artístico. No solo eso, "La comisión" es un relato verosímil, propio de las ciudades modernas de hoy, en las que las crónica rojas de los tabloides dan cuenta, cada día, de la ocurrencia de hechos tanto o más trágicos como los que desfilan por las páginas de este cuento. Los móviles últimos de estas tragedias que envuelven generalmente, pero no solo, a los sectores de menos recursos económicos de las urbes actuales, tienen que ver con factores como la violencia familiar, el machismo, la pobreza, la tugurización, la desnutrición, la ignorancia, los problemas psicológicos, la influencia de la denominada televisión "basura" entre otros. En esta desgracia, que ubica a Valento como el protagonista, también el personaje femenino sufre la mayor violencia y su cuerpo es destruido con frialdad por quien es su pareja en el hogar menesteroso que ambos comparten.

6 Suponemos que es el escritor Sigifredo Burneo Sánchez (Piura, 1952); aunque los tres relatos son igualmente valiosos y merecen estudios específicos. 
Los periodistas actuales son los testigos o los investigadores de estas historias macabras que "venden bien" y - como Darío Guerra- deben elegir entre contarlas o guardar silencio. Pero como su oficio es informar tienen que enfrentarse a los hechos más espeluznantes y dar cuenta de ellos porque ese es su trabajo. A menudo ha ocurrido en la vida real que los propios "hombres de la noticia" como se les llama -aunque hay muchas mujeres periodistas en los medios- han desencadenado la violencia o la han sufrido, y entonces ellos han sido los protagonistas de estos sucesos que, como ya hemos señalado, no son ajenos a la vida cotidiana de los habitantes de las ciudades "canibalizadas" del mundo actual.

\section{El trabajo de brichero en el Cusco imperial}

Concluiremos esta rápida incursión por los predios de nuestra actual narrativa breve con un acercamiento a otro relato valioso: "Cazador de gringas", del notable escritor sureño Mario Guevara Paredes (Cusco, 1956). ${ }^{7}$ Este texto es tan sorprendente $\mathrm{y}$ original como los anteriores, pero agrega algunos aspectos que enriquecen nuestra percepción del ámbito humano de la ciudad serrana andina por antonomasia, Cusco, pues aunque el narrador de esta curiosa anécdota nunca menciona el nombre del lugar donde ocurren los sucesos, otros indicios del propio texto sí nos permiten imaginar a la Ciudad Imperial como el espacio en el que un singular personaje ejerce su no menos raro oficio: el de brichero.

El término "brichero" no aparece en el Diccionario de la lengua española de la Real Academia, pero existe ya en los textos literarios y es una de las muchas palabras que se han formado a partir de una voz inglesa, o de la deformación de esta, como ocurre con el conocido vocablo "guachimán", cuyo significado comprendemos todos los que habitamos una ciudad como Lima u otras del Perú, en la que pululan miles de "guachimanes". En cambio, los "bricheros" parece que solo se pasean por calles, plazoletas, peñas y cafetines del Cusco.

Una acepción bastante exacta del citado término es, precisamente, la de "cazador de gringas". En palabras más formales "brichero" es el joven cusqueño que se dedica a seducir "gringas",

7 El relato comentado pertenece al libro Cazador de gringas y otros cuentos. Cusco: Municipalidad del Cusco, 1995. Nosotros hemos manejado la versión transcrita en la ya citada antología del cuento peruano de Ricardo González Vigil. 
es decir, mujeres de piel blanca, de procedencia norteamericana o europea, ${ }^{8}$ pues esa es la actividad de la que vive el personaje narrador de esta historia.

Y se la explica con detalles y una calculada inocencia al jefe de la comisaría, lugar donde ha sido conducido por golpear a una "nórdica" a la que había conquistado la noche anterior a la de su declaración, y con la que pensaba pernoctar en un hostal. En circunstancias en que se

... disponía a realizar el contacto final, usted me entiende, ocurrió lo inesperado. La gringa, abriendo desmesuradamente los ojos, se desprendió con violencia de mis brazos y, saltando de la cama, prorrumpió a gritar y lloriquear de una forma tan escandalosa que despertó al hostal.

Empero, el lector no se entera sino al final del relato del lugar donde se lleva a cabo la reunión del brichero y de la persona que escucha, sin interrumpir, las palabras del personaje que hace una explicación y hasta una apología de su modus vivendi.

Veamos la exposición inicial que le hace al comisario de la policía que es su oyente "formal":
Como le contaba, la gente nos ve como a bicho raro. Cuando camino por la calle bien aparrado de una gringa, al instante percibo sus miradas que dicen "feo y enano y con una gringa mamacita". Pero usted sabrá que no es nada fácil computar gringas.

Este oficio, no se ría, aunque no crea, es un oficio como cualquier otro que tiene ventajas y desventajas.

Y después de este discurso de presentación, el declarante realiza un recuento de los aspectos positivos y negativos que conlleva esta actividad en una ciudad a la que llegan diversas clases de "gringas" con el propósito de conocer los atractivos turísticos de Cusco y alrededores, pero también con el anhelo de vivir una experiencia amatoria con un andean-lover, como se denomina a sí mismo y a sus congéneres el personaje que cuenta, sin mayor inhibición, sus peripecias laborales y "accidentes de trabajo", como el que ha sufrido, por ejemplo, con la nórdica a la que golpeó en el hostal.

Precisamente, la línea principal del relato consiste en detallar el modo en que conoció y sedujo a la última de sus "presas". Las expresiones con que describe el encuentro con ella son muy sugerentes y vale transcribirlas:

8 La voz gringo(a) sí está registrada en el Diccionario de la lengua española (Real Academia Española. Vigésima segunda edición. Madrid: Espasa Calpe, 2001) con los significados que todos conocemos, y en el relato que estamos comentando aparece con esos significados. 
¿Quiere saber sobre la extranjera de anoche? Bueno, a esa gringuita la conocí en la taberna Qhatuchay. Apenas ingresé al local, la vi y me dije: así me la recomendó el médico; no se ría, es cierto, era bonita la fulana; usted la conoce y no me dejará mentir.

Con la misma desenvoltura continúa contando la forma en que se acercó y entabló relación con su víctima y ello permite conocer las estrategias que utiliza en la tarea de conquistar gringas. La principal de ellas consistió en

... convencerla de que este encuentro no era casual, sino que se debía al magnetismo que irradia esta ciudad, haciendo posible que esta noche nos encontráramos, pues hacía tiempo la conocía en sueños. Sonriendo trató de explicarme sobre los sueños, citando no sé si a Jung o Adler. Como ve, la gringa intentaba conducirme al campo de la psicología. Entonces, para trastocarle sus teorías, le manifesté que como iniciado en la práctica del mundo andino, tenía otra manera de percibir la realidad.

El brichero también informa a su oyente que no se limitó a perorar acerca de su condición de "iniciado" y de "elegido", sino que complementó su labor persuasiva con el consumo de "cervecitas que ella necesariamente tenía que pagar" y con el baile de melodías de huayno, salsa y rock. El resultado de este trabajo profesional del "cazador" fue positivo, pues
... al final, la gringa quedó convencida de que este encuentro era mágico y por efecto de la conversación y la cerveza, afirmaba ser la reencarnación de una valkiria que se había perdido en el tiempo.

Lamentablemente para el personaje narrador, la aventura, como ya hemos adelantado, no concluyó bien porque su acompañante, quizá por el mismo efecto de la cerveza, reaccionó de un modo violento precisamente cuando todo parecía que iba a culminar bien. Se produjo un intercambio de agresiones físicas entre ambos y como consecuencia de ello el brichero asestó a su acompañante un golpe que la dejó inconsciente. La policía llegó hasta la habitación y restableció el orden, aunque ello implicó golpear e inmovilizar al agresor. Este, después de haber dado su versión de los hechos y de deslindar su responsabilidad, se dirige a su oyente con estas palabras que son, también, las últimas del relato: "Ahora que se convenció de mi inocencia y de lo jodido que es ganarse la vida en este país, no dudará en dejarme en libertad, señor comisario".

Como ya hemos señalado, "Cazador de gringas" es un relato que muestra artísticamente algunos personajes, espacios, sucesos y situaciones que son parte del espacio urbano del Cusco, una ciudad enclavada en el corazón de los Andes peruanos, pero que por razones de su milenaria riqueza histórica 
y cultural y también por efectos de la llamada globalización, acentuada en las últimas décadas, ha devenido, cada vez más, en una ciudad cosmopolita; en un crisol donde se mezclan culturas, sangres, idiomas, bailes de los más diversos lugares del mundo. Y en ese hervidero humano el brichero es un personaje que no podía faltar. Guevara lo retrata magistralmente con su pluma y lo hace vivir una anécdota verosímil y aleccionadora.

Detrás de la aventura de este personaje hay un drama humano y laboral, pero, a la vez, su existencia es fruto de la realidad heterogénea en que ha devenido una ciudad como el Cusco. Ese pequeño mundo globalizado que es la capital arqueológica de América, ha hecho posible que surja un tipo humano y cultural como el que acabamos de conocer gracias al relato comentado. Por ello, quizá sea pertinente concluir con estas líneas que tratan de explicar el sentido de la existencia de este exótico espécimen humano. Dice, al respecto, el escritor peruano Eduardo González Viaña, que:

... un brichero es un cazador de gringas, un andean lover, un irresistible conquistador de extranjeras. Me han dicho que la palabra viene del inglés, bridge, puente, lo que confiere al brichero una calidad que en vez de ser la de mantenido, resulta en la de constructor de lazos perdurables entre el Perú de los Incas y las naciones gringas... El brichero es una especie de indio profesional cuyo atractivo radica en todo lo próximo que puede estar al color local que le confiere exotismo y mucha suerte.?

Concluimos, pues, este breve recorrido por los mundos posibles y verosímiles que nos presentan las páginas de algunos de nuestros más notables cuentistas actuales. Cada uno de ellos nos ofrece un singular punto de vista acerca del universo de las ciudades subdesarrolladas y, a la vez, globalizadas del Perú de hoy. El lector se habrá encontrado, quizá, con algunos de estos personajes, sucesos, situaciones, espacios que caracterizan a las urbes de principios de milenio. Después de todo la realidad y la ficción se dan la mano a cada momento y a veces la una imita a la otra, y viceversa. Esperamos que estas líneas lo lleven a recorrer los caminos de la ficción narrativa peruana actual. Vale la pena emprender el recorrido personal para nutrirse directamente de lo que nuestros cuentistas nos ofrecen.

9 Hemos transcrito estas palabras de González Viaña de la citada antología de Ricardo González Vigil. 